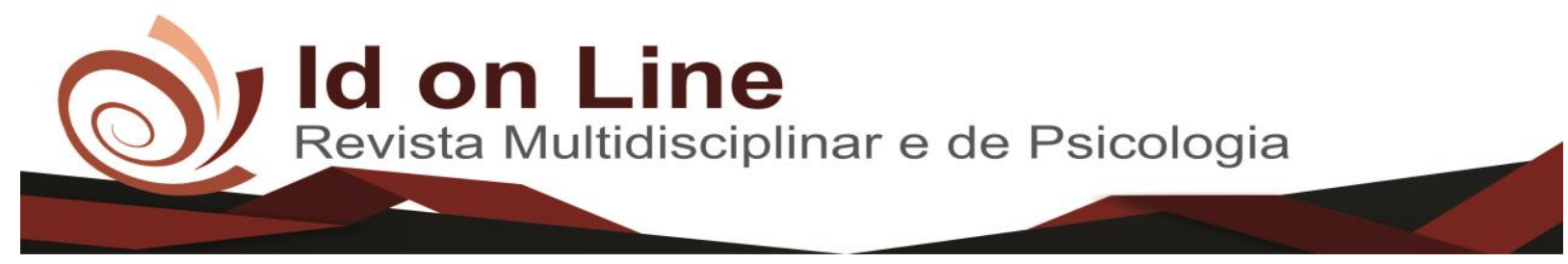

Comment

\title{
Afefobia em Foco: filme Repulsão a partir do prisma psicanalítico
}

Débora dos Santos Silva ${ }^{1}$; Cícera Maria dos Santos Gomes ${ }^{2}$; Ana Olívia de Oliveira Marinho ${ }^{3}$

Resumo: O termo afefobia representa aqueles que sentem uma forte angústia com sintomas de taquicardia, sudorese, sensação de punhalada no peito, náusea e tremores quando tocados. Estes sintomas podem variar de pessoa para pessoa, sendo que algumas podem senti-los até em contatos/toques sociais: como um simples aperto de mão. A evitação fóbica tende a ficar evidente na idade adulta quando as pessoas geralmente elegem um objeto amoroso. Tende a surgir com intenso sofrimento psíquico a depender de cada história de vida e da estruturação clínica. Para abordar o tema, utilizou-se o recurso do estudo de caso, onde foi feito a descrição e análise da personagem principal do filme Repulsão, Carole Ledoux, no intuito de vislumbrar e melhor entender, a partir da ficção e norteada pela psicanálise, um assunto que causa bastante sofrimento em quem padece desta problemática afetiva. Conclui-se sinalizando a importância da associação livre, da fala em análise, para que se possa lidar com os afetos e possibilitar, por acréscimo, a cura de sintomas que causem adoecimento.

Palavras-chave: Afefobia; Carole Ledoux; Amor; Loucura; Associação Livre.

\section{Haphephobia in Focus: The Movie Repulsion from the psychoanalytic prism}

\begin{abstract}
The term Haphephobia represents those who feel a strong anguish with symptoms of tachycardia, sweating, stabbing sensation in the chest, nausea and tremors when touched. These symptoms may vary from person to person, and some may even feel it in social contacts / touches: like a simple handshake. Phobic avoidance tends to become evident in adulthood when people generally choose a loving object. It tends to arise with intense psychic suffering depending on each life history and clinical structure. In order to approach the theme, the case study resource was used, where the description and analysis of the main character of the movie Repulsion, by Carole Ledoux, was made, in order to glimpse and better understand, from fiction and guided by psychoanalysis, a subject that causes enough suffering in those who suffer from this affective problem. It concludes by pointing out the importance of free association, of speech under analysis, so that we can deal with the affections and enable, in addition, the cure of symptoms that causes the illness.
\end{abstract}

Keywords: Haphephobia ; Carole Ledoux; Love; Madness; Free Association.

\footnotetext{
${ }^{1}$ Graduada em Psicologia pelo Centro Universitário Dr. Leão Sampaio - UNILEÃO. Psicóloga com abordagem psicanalítica. Especialista em Educação Inclusiva com Ênfase em Atendimento Educacional Especializado e em Prática Docente do Ensino Superior pelas Faculdades Integradas de Patos - FIP. Atualmente é integrante do Cartel Lacaniano sobre Seminário VIII, A Transferência, pela Invenção Freudiana (Escola de Psicanálise). Telefone: (88) 9 88649985. E-mail: deborassilva25@gmail.com;

${ }^{2}$ Doutora em Serviço Social pela Universidade Federal do Pernambuco - UFPE (2012), mestre em Serviço Social - UFPE (2004), bacharel em Serviço Social - UFPE (2001). Consultora em meio ambiente e educação ambiental pela Travessia Cursos e Assessoria. Email: gomes_cicera@yahoo.com.br;

${ }^{3}$ Médica pela Universidade de Pernambuco - UPE. Contato: anamarinho89@gmail.com.
} 


\section{Introdução}

Segundo Lacan, o Amor e a Verdade possuem estrutura de ficção. Fazem semblante a fim de esconder, de velar a falta própria à estrutura, do real não passível de simbolização. É preciso, então, encarar que, assim como Kant um dia mencionou sobre a impossibilidade de se conhecer o númeno e sim apenas os fenômenos, similarmente, o amor, a verdade ou o motor dos discursos produtores de laços sociais permanecerão sempre incompletos, não-todo(s).

Porém, mesmo diante desta impossibilidade da completude ou da relação sexual, as pessoas continuam amando, falando, odiando, mentindo e, tentando dizer a verdade; em suma, usando a linguagem de modo a exercer efeito/poder sobre o mundo.

No quesito sujeito-objeto direcionado para os relacionamentos amorosos, a psicanálise há muito tem demonstrado a existência de afetos pouco comuns (para não dizer a-normais). No presente trabalho, aponta-se para uma situação vivenciada por certas pessoas que, talvez, de certa forma, tenham alcançado um elevado nível de sublimação ou idealização dos objetos a ponto de não conseguirem ou recalcarem a libido que poderia ser direcionada para estes objetos. Não conseguem olhar o outro como ser sexual, apenas como sujeitos.

Não obstante, acalentam o amor no mais recôndito de seu desejo, têm vontade de manter relacionamentos íntimos, porém, quando a oportunidade sinaliza no real, a angústia dá sinal e a fuga ou esquiva é acionada.

Estes casos não são tão isolados como podem parecer num primeiro momento e podem causar estranhamento para a pessoa que padece deste afeto e para familiares, amigos, colegas. Enfim, para os que compõem o círculo de convivência do sujeito em pauta.

Atualmente esta patologia recebe o nome de afefobia. Mas é fato que deve ter existido ao longo da história da humanidade. Tem até uma expressão retirada da filosofia e que descreve bem o que está sendo dito, a saber: amor platônico. Amor, na medida em que os componentes admiração e desejo sexual podem estar presentes. Platônico, em virtude de sinalizar um sentimento que parece transcender o exercício da sexualidade, contentando-se, desse modo, na sublime atividade de sonhar e devanear o que não se pretende realizar. 


\section{Tópicos sobre afefobia}

O termo afefobia representa aqueles que sentem uma forte angústia com sintomas de taquicardia, sudorese, sensação de punhalada no peito, náusea e tremores quando tocados. Estes sintomas podem variar de pessoa para pessoa, sendo que algumas podem senti-los até em contatos (toques) sociais como um simples aperto de mão. Intensificam-se na idade adulta quando as pessoas elegem um par romântico (em namoro, casamento ou "fica"), mas suas primeiras manifestações geralmente surgem na adolescência.

Costuma-se encontrar tais casos em sujeitos com neurose obsessiva. Porém, também pode ocorrer na histeria, aparecendo como uma espécie de evitação fóbica. Também pode surgir na estrutura psicótica. Alguns podem ter sofrido abuso sexual na infância, mas não caracteriza todos os casos. Talvez uma educação rígida, somada a princípios religiosos fundamentalistas, pode vir a desencadear tal problemática. Alguns podem lidar bem com o fato, enquanto outros se sentirem infelizes, diferentes e frustrados por experimentarem tantas inibições. No entanto, como Freud cita em sua conferência XXIII (1996/1917 [1916-17]), deve estar subjacente a esta, como a toda problemática psiconeurótica, uma série complementar, qual seja: a fixação da libido, a constituição herdada e a disposição adquirida na infância.

Nesta conferência, Freud (1996/1917 [1916-17], p. 364), faz o seguinte esquema: Causação da Neurose $=$ Disposição devida à fixação da libido + Experiência casual (traumática) [no adulto]

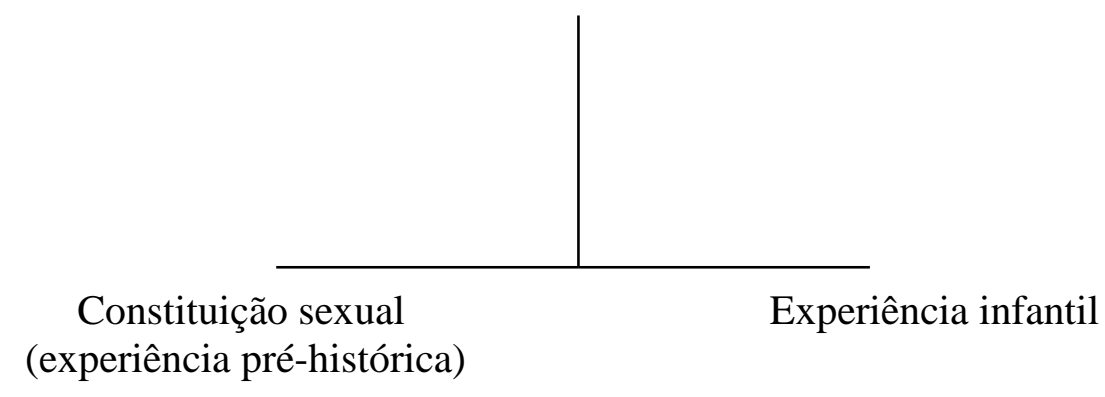


Com a descrição a seguir de um filme intitulado Repulsão, que enfoca a falta de interação afetiva (no campo sexual/amoroso), talvez os conceitos tratados possam fazer mais sentido. Leva-se, portanto, em consideração que tudo é significativo quando vem do ser falante, embora nem tudo seja significante, podendo-se, então, os ditos, os dizeres e os atos pertencerem à lógica da lalangue; ou seja, do corpo falante.

\section{Estudo de caso: personagem Carole Ledoux do filme Repulsão}

Repulsion, Repulsão ou Repulsa ao sexo, como foi traduzido para o português, é um filme britânico, de 1965, do diretor Roman Polanski. O filme é ambientado em Londres e conta a história da manicure Carole Ledoux que, mesmo possuindo grande beleza e ser bastante cortejada pelos homens, se mantém afastada das potenciais relações amorosas.

Quase no inicio do enredo surge um retrato de família onde Carole (quando criança) aparece olhando para o nada, enquanto o resto da família posa para a foto. Aqui o diretor conduz o olhar do espectador para o tema central do filme, a saber: a falta de interesse da protagonista para as coisas banais da vida: como tirar uma foto de família.

Ela reside com a irmã Hélène Ledoux num apartamento. Carole todos os dias vai para o trabalho, tem uma relação fraternal com a irmã e conserva algumas amizades, mas sem demonstrar nenhum tipo de prazer ou desejo pelas situações que ocupam o pensar das moças em sua idade, tais como: conhecer alguém, paquerar, namorar e casar.

A trama fílmica não explica o que ocorreu com a moça no passado. Mas, o fato é que, se no antigo retrato ela já se apresentava sem sabor pela existência, isso sinaliza então que sua problemática se arrastava por longo tempo.

A irmã mais velha tem um namorado (Michael) e o leva constantemente para dormir no apartamento onde elas residem. O homem é casado e, portanto, eles têm um relacionamento clandestino. Muitas vezes Carole se vê irritada e angustiada com a situação que a irmã lhe impõe.

Irritada, porque o cara além de ser casado é ridículo, no entender de Carole, pois coloca sua escova de dente no compartimento onde elas guardam as suas escovas, sem falar que ocupa o território, como se o pertencesse. 
Angustiada, porque passa noites e noites sem dormir, em virtude do barulho que o casal faz em suas jornadas sexuais noturnas (sons esses que colocam a imaginação e fantasia da jovem para funcionar de uma maneira totalmente equivocada, pois que provavelmente ainda não estava preparada emocionalmente para presenciar tais ruídos).

Entretanto, sua curiosidade sexual foi despertada por toda aquela situação vivenciada em casa. Nesse ínterim, surge Colin que se interessa demasiadamente por Carole. Ele sempre a vê passar indo para o trabalho e tenta chamar sua atenção. Porém, a moça se conserva sempre muito fria, sem emoção.

Talvez esta atitude de mulher narcísica ${ }^{3}$ tenha despertado nele um interesse maior. Daí inicia uma série de investidas, pois precisa conquistar a garota. Convida-a para jantar de maneira insistente, perde o interesse nos amigos e nas outras garotas. Fica com o pensamento totalmente voltado para Carole, mesmo ela dizendo não.

\section{Amor e Loucura}

Essa espécie de paixão desmedida nos faz lembrar a fábula contada por La Fontaine (2007) sobre o enigma do amor com seu misto de loucura e cegueira frente ao objeto amado. Neste sentido, a fábula narra um evento ocorrido entre Amor e Loucura que, estavam a brincar quando ocorreu um desentendimento. Amor então quis recorrer ao conselho dos deuses, porém, Loucura, impaciente, quis resolver a desavença desferindo um golpe em Amor. A coronhada foi tão violenta que cegou Amor. Os Deuses, por conseguinte, decidiram castigar Loucura a servir de guia ao Amor.

Da mesma forma, o rapaz mendigava o amor de Carole. E assim, um dia, ela aceitou sair com ele. Neste encontro um beijo aconteceu. Todavia, ao ser beijada a moça se sentiu estranha e saiu correndo para casa, e ao chegar foi direto lavar a boca. Desse dia em diante ela não quis falar com Colin. Sua aversão aos homens aumentou. Esta aversão foi ainda mais incentivada pelos relatos que ouvia em casa (da irmã) e no trabalho (das colegas e clientes) sobre o modo descortês que os homens tratavam as mulheres.

Neste sentido, se para Freud:

\footnotetext{
${ }^{3}$ Segundo Freud (1914/2004) mulher narcísica é aquela que se mantém indiferente à sedução masculina.
} 
O estado de paixão consiste em um transbordamento da libido sobre o objeto. Este estado tem o poder de suspender recalques e de restaurar perversões. Eleva o objeto sexual à categoria de um ideal sexual [...]. (FREUD, 1914/2004, p. 118)

Em Carole, não obstante, como num adoecimento neurótico (histérico grave), as repressões sexuais triplicaram. Porém, a energia recalcada retorna no simbólico encarnado no sintoma. Ela começa a ter alucinações. Vê as paredes rachando. Fica desligada das situações à sua volta. Sempre na hora de dormir, acha que está sendo estuprada por um homem.

O sofrimento da garota aumenta consideravelmente quando a irmã, que para ela é um porto seguro, viaja com o namorado nas férias. O que leva a crer que, talvez, o formato de amor objetal/sublimado que Carole tem por Hélène, amor acalentado desde a infância, não tenha conseguido se deslocar para um objeto externo masculino.

Assim, quando a irmã viaja, a garota cai doente, deixa de trabalhar. Além de não amar, deixa também de trabalhar. As alucinações aumentam. Encontra a camisa de Michael jogada no chão do banheiro e começa a cheirá-la, em seguida sai correndo para lavar o rosto. Veste os vestidos da irmã e usa seu batom. Para de se alimentar e de limpar a casa onde mora. Tudo fica cinza, nebuloso, dark.

Colin, cego e louco de amor, resolve ir à casa de Carole para se declarar, depois de muito ligar e sem experimentar resposta. Entretanto, a jovem permanece apática ao escutar atrás da porta (já que não quis abri-la) os gritos do amor de Colin chamando por ela. Amor este a que ela estava impedida de corresponder.

Um forte egoísmo protege contra o adoecimento, mas, no final, precisamos começar a amar para não adoecer, e iremos adoecer se, em conseqüência de impedimentos, não pudermos amar [...] (FREUD, 1914/2004, p. 106)

\section{Associação livre: uma regra de ouro}

Havia muitos bloqueios na psique de Carole para o sexo, paixão e amor. A cura pelo amor, experimentada por muitos neuróticos, através do tratamento psicanalítico ou mesmo pela simples arte de viver, não pôde se concretizar para ela. Quiçá pelo fato de não ter podido falar sem reservas, em associação livre (ou seja, num dizer aberto, alheio às censuras e ao certo e errado. E estranho ao controle consciente), sobre aquilo que a perturbava. 
Nesta perspectiva, é interessante dar o exemplo da personagem principal de Stefan Zweig, em 24 horas na vida de uma mulher (1935), que relata sua história indecorosa de décadas passadas, mas que ainda pulsava em sua mente como uma ferida que não cicatrizava, para um estranho que conheceu em uma roda de conversa de um hotel. Durante a roda de conversa este estranho tomou partido de uma senhora que havia fugido naquele momento com um sedutor que não conhecia e deixado para trás um casamento antigo e sólido. Assim, como a mulher sentiu nele um support, alguém que não julgava as pessoas por suas ações, então, pensou poder partilhar a sua experiência, guardada a sete chaves, e dessa forma abrandar um pouco, em catarse, aquelas fortes lembranças. Foi o que fez. Depois daquilo se sentiu mais aliviada. Depois daquilo não mais viu o estrangeiro que tão bem ouviu suas confissões.

Com efeito, de modo geral, existe uma grande resistência por parte das pessoas em perceber e auxiliar aqueles que apresentam um comportamento ou afetos diferentes que causem sofrimento. Às vezes a própria pessoa pensa que conseguirá lidar sozinha com seus problemas, e, quando sabe não conseguir, às vezes pode não procurar ajuda especializada por questões pecuniárias ou de outra esfera. Destarte, Freud menciona que

[...] a incapacidade que o doente tem de amar, resultante da extensão de seus recalques, se opõe [...] [à cura pelo amor]. Entretanto, se pelo tratamento lograrmos libertá-lo até certo ponto desses recalques, nos defrontaremos muitas vezes com o resultado involuntário de que o paciente se retira do tratamento para fazer uma escolha amorosa [...]. Até poderíamos nos contentar com esse resultado se tal solução não trouxesse consigo todos os perigos de uma dependência opressiva para com a pessoa amada. (FREUD, 1914/2004, p. 118)

Neste prisma, o desenrolar do filme se confunde com o que Lacan, em seu seminário oito sobre a Transferência ${ }^{4}$, chama de Atè: que é o "infortúnio, a coisa que se crucifica e jamais se esgota, a calamidade que está por trás de toda aventura trágica [...]” (LACAN, 1961/2010, p. 142).

Ou seja, o longa-metragem não tem o final feliz da Gradiva, romance de W. Jensen que Freud toma como exemplo de cura pelo amor em seu estudo Delírios e sonhos na Gradiva de Jensen (1907[1906]1996). Cura que se assemelha ao que acontece num tratamento psicanalítico, mas com a diferença que neste romance, a jovem Zoe Bertgang, que faz o papel de analista, é amiga/amor de infância do jovem arqueólogo Norbert Hanhold.

\footnotetext{
${ }^{4}$ Este seminário é todo dedicado ao estudo da transferência que é um conceito fundamental da psicanálise. Nele, Lacan se utiliza da obra $O$ banquete, de Platão, para, através de uma série de comparações e distinções, demonstrar que a transferência e o desejo do analista, no setting psicanalítico, são semelhantes ao conceito de amor (dos e) aos jovens que desejam sair das trevas da ignorância e que buscam um saber: sempre inalcançável, visto não ter fim determinado e não pertencer a ninguém. 
Auxilia-o a desfazer suas repressões e recalques e a completar os lapsos de memória com as lembranças certas, recordadas, repetidas e elaboradas de maneira a que eles possam retomar o amor infantil agora revivido em sexualidade genital e amor adulto.

Circunstância que, vale ressaltar, não deve ocorrer dentro de uma psicanálise, onde o analista deve instrumentalizar a transferência de seu analisante através do desejo de analisá-lo e do entendimento dos aspectos necessários de passagem entre alienação/separação e destituição subjetiva. Mantendo, assim, a transferência em suspensão, em abstinência, ao fazer semblante de objeto $a$, causa de desejo, e ao mesmo tempo sinalizando para este analisante, ao longo do tratamento, a não existência do agalma ou Grande Outro, deste ser que possa tamponar definitivamente a falta e/ou desamparo, próprio à estrutura.

É assim que Sócrates, no Banquete de Platão, irá se portar frente às revelações de amor de Alcebíades. O banquete é uma obra que trata do amor: o que é o amor? E cada personagem deve fazer um elogio ao amor. Porém, Alcebíades, que chega sem ser convidado e totalmente embriagado, resolve fazer um elogio a Sócrates. Elogio que pode ser considerado tanto como uma afronta ressentida quanto como um amor destemperado.

Logo,

[...] O analista é e não é Sócrates: o analista está em consonância com Sócrates na medida em que ele sabe não possuir o objeto que lhe supõe o analisando, e ele não é Sócrates, pois o analista sabe que tal objeto não se encontra em lugar nenhum, contrário a Sócrates que, aparentemente, o atribui a Agaton [...] É certo que Sócrates fornece todos os indícios de que ele não tem o objeto, contudo, isto não significa que ele acredite na não-existência de tal objeto. (GOBBATO, 2001, p. 110)

Assim, por Carole não ter tido um apoio, um acompanhamento especializado e ter mergulhado cada dia mais em uma solidão de pensamentos, ações e medos não fundamentados na realidade, então, acaba matando Colin que foi manifestar todo seu amor por ela. Esconde o corpo no banheiro. Depois, assassina o senhorio (dono do apartamento em que mora com a irmã), no momento em que ele lança uma investida sexual para ela, que se encontra sozinha, dentro de casa, quando ele vai cobrar o aluguel.

Posteriormente a irmã regressa de sua viagem com Michael e encontra a casa revirada, o corpo de Colin dentro do banheiro e Carole, no quarto de Hélène, debaixo da cama, toda ensanguentada e visivelmente off air. 


\section{Considerações finais}

O que pensar, então, de relationships desse tipo. Servem pura e simplesmente de tema para compor filmes de terror psicológico como este? A história do sintoma de Carole é de alguém com estruturação neurótica ou causa dúvida durante a leitura deste texto? A película apresentada é da década de 1960, porém, a questão abordada pode ser deslocada para a contemporaneidade? São perguntas que fazemos no fim de uma exposição como esta. Perguntas retóricas, pois cabe a cada um refletir ou não sobre tudo aquilo que passa por sua retina.

Neste sentido, com a análise da personagem principal do filme Repulsion, buscou-se trazer à tona alguma discussão acerca da afefobia, um tema pouco estudado e com escassa bibliografia. Sendo que existem casos não só na ficção, mas relatados e conhecidos pelas autoras deste texto e que apontam para algo além do simples recalque da pulsão sexual (em sua versão erótica). No entanto, muitas pessoas optam por esconder seu padecimento, tal como as anoréxicas fazem com sua evitação frente à comida.

Diante disso, aponta-se a importância da associação livre, da fala em análise, para que se possa suportar e enfrentar certas problemáticas e possibilitar, por acréscimo, a cura de sintomas que causem adoecimento. Pretendeu-se, então, gerar curiosidade no leitor sobre tal afeto no intuito de ampliar o debate e causar mais pesquisas e discussões sobre o assunto.

\section{Referências}

FREUD, Sigmund. À guisa de introdução ao narcisismo (1914). In. Escritos sobre a psicologia do inconsciente (1911-1915). Rio de Janeiro: Imago Ed., 2004.

Conferências introdutórias sobre psicanálise (Parte III) (1915-1916). Edição standard brasileira. Rio de Janeiro: Imago, 1996.

Delírios e sonhos na Gradiva de Jensen (1907[1906]). In. "Gradiva” de Jensen e outros trabalhos. Edição standard brasileira. Rio de Janeiro: Imago, 1996.

GOBBATO, Gilberto Gênova. Transferência: amor ao saber. Ágora, v. IV n. 1, 2001.

LACAN, Jacques. O seminário, Livro 8: A transferência. Rio de Janeiro: Zahar, 2010. 
LA FONTAINE, Jean de. O amor e a loucura. In: Os melhores contos de loucura. Flávio Moreira da Costa (Org.). Rio de Janeiro: Ediouro, 2007.

REPULSION. Filme britânico. Diretor Roman Polanski. Ano de lançamento: 1965.

ZWEIG, Stefan. 24 horas na vida de uma mulher (1935). Editora L\&PM, 2007.

\section{Como citar este artigo (Formato ABNT):}

SILVA, Débora dos Santos; GOMES, Cícera Maria dos Santos; MARINHO, Ana Olívia de Oliveira. Afefobia em Foco: filme Repulsão a partir do prisma psicanalítico. Id on Line Revista Multidisciplinar e de Psicologia, 2018, vol.12, n.39, p.786-795. ISSN: 1981-1179.

Recebido: 28.01.2018

Aceito: 29.01 .2018 